\title{
Generation of Rules for Student Feedback System by the Use of Rough Set Theory
}

\author{
Sujogya Mishra \\ Research scholar, \\ Utkal University \\ Bhubaneswar-751004, India
}

\author{
Shakti Prasad Mohanty \\ Department of Mathematics \\ College of Engineering and \\ Technology \\ Bhubaneswar-751003, India
}

\author{
Sateesh Kumar Pradhan \\ Department of Computer \\ Science \\ Utkal University \\ Bhubaneswar-751003, India
}

\author{
Radhanath Hota \\ Department of Computer Science \\ Odisha University of Agriculture Technology \\ Bhubaneswar-751003, India
}

\begin{abstract}
Student feedback is always a challenge for the teacher. In general method student usually in our country that is India shy in nature, usually never ask question to the teacher when he or she had any doubts in their mind, when question of feedback come they usually give negative feedback at the door of higher authorities. In this we develop rules using rough set to testify confusing state of the student mind. To generate the rules we are taking Rough Set as a tool
\end{abstract}

\section{Keywords}

Rough Set Theory, Student feedback related data, Granular computing, Data mining.

\section{INTRODUCTION}

The growth of data size and number of existing databases are far exceeds the ability of humans to analyze it. Which creates an urge to ex-tract knowledge from databases[1] student databases has accumulated large volume of information about the teachers and students and their interrelation. Student feedback knowledge is basically depends upon the pattern and relationship of the accumulated data. Feedback data analysis often deals with incomplete knowledge. In the present scenario intelligent method[2] means data analysis based upon strong assumptions knowledge about dependencies, probability distributions and large number of experiments which unable to derive conclusions from incomplete knowledge, or cannot proceed further with the inconsistent pieces of information. The standard intelligent method available for student database analysis data analysis are neural network[3] Bayesian classifier [4] genetic algorithms[5] decision trees [6] fuzzy set [7] . Rough set theory, Professor Z. Pawlak [8] .The theory of rough sets is a mathematical tool for deriving inference from un-certain and incomplete data base information. The rough set reduction algorithms contribute to approximate the decision classes using possibly large and simplified patterns [9]. Dempster-Shafer theory or statistical methods, rough set analysis requires no external parameters and uses only those information present in the given data [10].In this paper we discusses how rough set theory is useful in analyzing large student data, and for generating classification rules from a set of observed samples . Using rough set reduction technique we find all reducts of the data which contains the minimal subset of attributes that are associated with a class label for classification.

\section{PRILIMINARIES}

\subsection{Rough Set}

Rough set theory as introduced by Z. Pawlak[8] is an extension of conventional set theory that support approximations in decision making.

\subsubsection{Approximation Space}

An Approximation space is a pair $(\mathrm{U}, \mathrm{R})$ where $\mathrm{U}$ is a non empty finite set called the universe $\mathrm{R}$ is an equivalence relation defined on $\mathrm{U}$.

\subsubsection{Information System}

An information system is a pair $\mathrm{S}=(\mathrm{U}, \mathrm{A})$, where $\mathrm{U}$ is then onempty finite set called the universe, $\mathrm{A}$ is the non-empty finite set of attributes

\subsubsection{Decision Table}

A decision table is a special case of information systems $\mathrm{S}=(\mathrm{U}$, $\mathrm{A}=\mathrm{C} \mathrm{U}\{\mathrm{d}\})$, where $\mathrm{d}$ is not in C. Attributes in $\mathrm{C}$ are called conditional attributes and $\mathrm{d}$ is a designated attribute called the decision attribute

\subsubsection{Approximations of Sets}

Let $\mathrm{S}=(\mathrm{U}, \mathrm{R})$ be an approximation space and $\mathrm{X}$ be a subset of $\mathrm{U}$. The lower approximation of $\mathrm{X}$ by $\mathrm{R}$ in $\mathrm{S}$ is defined as $\underline{\mathrm{RX}}=$ $\{\mathrm{e} \varepsilon \mathrm{U} \mid[\mathrm{e}] \varepsilon \mathrm{X}\}$ and The upper approximation of $\mathrm{X}$ by $\mathrm{R}$ in $\mathrm{S}$ is defined as $\quad \overline{R X}_{=}=\{\mathrm{e} \varepsilon \mathrm{U} \mid[\mathrm{e}] \varepsilon \mathrm{X}\}$ where [e] denotes the equivalence class containing e. A subset $\mathrm{X}$ of $\mathrm{U}$ is said to be $\mathrm{R}$ definable in $\mathrm{S}$ if and only if $\overline{R X}=\underline{\mathrm{RX}}$. A set $\mathrm{X}$ is rough in $\mathrm{S}$ if its boundary set is nonempty.

\subsection{Reduct and Core}

Let $\mathrm{S}=(\mathrm{U}, \mathrm{A}=\mathrm{C} \mathrm{U} \mathrm{D})$ be a decision table. A subset $\mathrm{R}$ of $\mathrm{C}$ is a reduct of $C$, if $\operatorname{POS}_{\mathbf{R}}(\mathrm{D})=\operatorname{POS}_{\mathrm{C}}(\mathrm{D})$ and $\mathrm{S}^{\prime}=(\mathrm{U}, \mathrm{RUD})$ is independent, ie., all attributes in $\mathrm{R}$ are indispensible in $\mathrm{S}$ '. Core of $\mathrm{C}$ is the set of attributes shared by all reducts of C. CORE(C) $=\cap \operatorname{RED}(\mathrm{C})$ where, $\operatorname{RED}(\mathrm{C})$ is the set of all reducts of $\mathrm{C}$. The reduct is often used in the attribute selection process to eliminate redundant attributes towards decision making. 


\subsection{Correlation}

Correlation define as a mutual relationship or connection between two or more things. The quantity $r$, called the linear correlation coefficient, measures the strength and the direction of a linear relationship between two variables. The linear correlation coefficient is sometimes referred to as the Pearson product moment correlation coefficient in honor of its developer Karl Pearson. The mathematical formula for its coefficient given by the formula

$$
r=\frac{n \sum x y-\left(\sum x\right)\left(\sum y\right)}{\sqrt{n\left(\sum x^{2}\right)-\left(\sum x\right)^{2}} \sqrt{n\left(\sum y^{2}\right)-\left(\sum y\right)^{2}}}
$$

\subsection{Different Types of Error}

1. Type 1 error-Rejecting a hypothesis even though it is true

2. Type 2 error-Accepting the hypothesis when it is false

3. Type 3 error-Rejecting a hypothesis correctly for wrong reason

\section{BASIC IDEA}

Basic idea for the proposed work is conceived from the general student database system for collection of feedback system. We initially consider 1000 samples, of feedback which was collected from various sources cases and seven conditional attributes such as Direct approach, indirect ,given assignment , Feedback on laboratory performance of student, Result of the end semester ,random selection from large sample size and collection of feedback testing student iq, Immidiate feedback just after single class end and it's values are defined as low ,moderate and high and decision attributes are positive. negative .We rename the attributes and it's values for better understanding $\left(\mathrm{a}_{1}, \mathrm{a}_{2}, \mathrm{a}_{3}, \mathrm{a}_{4}, \mathrm{a}_{5}, a_{6}, a_{7}\right)$ as conditional attributes ,$\left(b_{1}, b_{2}, b_{3}\right)$ as values of the conditional attributes and $\left(c_{1}, c_{2}\right)$ as decision attributes respectively.

\section{DATA REDUCTION}

Approximation: The starting point of rough set theory is the indiscernibility relation, generated by information concerning objects of interest. The indiscernibility relation is intended to express the fact that due to the lack of knowledge it is unable to discern some objects employing the available information Approximations is also other an important concept in Rough Sets Theory, being associated with the meaning of the approximations topological operations (Wu et al., 2004). The lower and the upper approximations of a set are interior and closure operations in a topology generated by the indiscernibility relation. Below is presented and described the types of approximations that are used in Rough Sets Theory.

a. Lower Approximation: Lower Approximation is a description of the domain objects that are known with certainty to belong to the subset of interest.The Lower Approximation Set of a set $\mathrm{X}$, with regard to $\mathrm{R}$ is the set of all objects, which can be classified with $\mathrm{X}$ regarding $\mathrm{R}$, that is denoted as $\mathrm{R}_{\mathrm{L}}$.

b. Upper approximation: Upper Approximation is a description of the objects that possibly belong to the subset of interest. The Upper Approximation Set of a set X regarding $\mathrm{R}$ is the set of all of objects which can be possibly classified with $\mathrm{X}$ regarding $\mathrm{R}$. Denoted as $\mathrm{R}_{\mathrm{U}}$

c. Boundary Region (BR): Boundary Region is description of the objects that of a set $\mathrm{X}$ regarding $\mathrm{R}$ is the set of all the objects, which cannot be classified neither as $\mathrm{X}$ nor $-\mathrm{X}$ regarding $R$. If the boundary region $X=\phi$ then the set is considered "Crisp", that is, exact in relation to R; otherwise, if the boundary region is a set $\mathbf{X} \neq \phi$ the set $X$ "Rough" is considered. In that the boundary region is $B R=R_{U^{-}}$ $\mathrm{R}_{\mathrm{L}}$.Application and analysis on the data set and rule generation being presented in the following tables. Table -1 is the initial table, and the process of analysis is present in the subsequent tables.

Initial Generation from the Collected data's Table-1

\begin{tabular}{|c|c|c|c|c|c|c|c|c|}
\hline$E$ & $a_{1}$ & $a_{2}$ & $a_{3}$ & $a_{4}$ & $a_{5}$ & $a_{6}$ & $a_{7}$ & $\bar{d}$ \\
\hline $\mathrm{E}_{1}$ & $\mathrm{~b}_{2}$ & $b_{2}$ & $b_{1}$ & $b_{1}$ & $b_{1}$ & $\mathrm{~b}_{2}$ & $\mathrm{~b}_{1}$ & $\mathrm{c}_{2}$ \\
\hline $\mathrm{E}_{2}$ & $\mathrm{~b}_{2}$ & $b_{2}$ & $b_{1}$ & $b_{3}$ & $b_{3}$ & $b_{2}$ & $b_{2}$ & $\mathrm{c}_{2}$ \\
\hline$E_{3}$ & $b_{1}$ & $\mathrm{~b}_{2}$ & $\mathrm{~b}_{2}$ & $b_{3}$ & $b_{3}$ & $\mathrm{~b}_{1}$ & $\mathrm{~b}_{2}$ & $\mathrm{c}_{1}$ \\
\hline $\mathrm{E}_{4}$ & $b_{1}$ & $\mathrm{~b}_{2}$ & $\mathrm{~b}_{2}$ & $b_{3}$ & $b_{3}$ & $b_{1}$ & $\mathrm{~b}_{2}$ & $\mathrm{c}_{1}$ \\
\hline $\mathrm{E}_{5}$ & $b_{3}$ & $b_{3}$ & $b_{3}$ & $b_{3}$ & $b_{2}$ & $b_{3}$ & $b_{2}$ & $\mathrm{c}_{2}$ \\
\hline $\mathrm{E}_{6}$ & $\mathrm{~b}_{1}$ & $\mathrm{~b}_{2}$ & $\mathrm{~b}_{2}$ & $\mathrm{~b}_{2}$ & $\mathrm{~b}_{2}$ & $b_{1}$ & $\mathrm{~b}_{2}$ & $\mathrm{c}_{2}$ \\
\hline $\mathrm{E}_{7}$ & $\mathrm{~b}_{2}$ & $\mathrm{~b}_{2}$ & $\mathrm{~b}_{2}$ & $\mathrm{~b}_{2}$ & $\mathrm{~b}_{2}$ & $b_{2}$ & $\mathrm{~b}_{2}$ & $\mathrm{c}_{1}$ \\
\hline $\mathrm{E}_{8}$ & $b_{1}$ & $\mathrm{~b}_{1}$ & $b_{1}$ & $b_{1}$ & $b_{1}$ & $b_{1}$ & $b_{1}$ & $\mathrm{c}_{2}$ \\
\hline $\mathrm{E}_{9}$ & $\mathrm{~b}_{1}$ & $\mathrm{~b}_{2}$ & $\mathrm{~b}_{2}$ & $b_{3}$ & $\mathrm{~b}_{3}$ & $b_{1}$ & $b_{3}$ & $\mathrm{c}_{1}$ \\
\hline $\mathrm{E}_{10}$ & $\mathrm{~b}_{1}$ & $\mathrm{~b}_{2}$ & $\mathrm{~b}_{2}$ & $\mathrm{~b}_{2}$ & $\mathrm{~b}_{2}$ & $b_{1}$ & $b_{2}$ & $\mathrm{c}_{2}$ \\
\hline $\mathrm{E}_{11}$ & $\mathrm{~b}_{2}$ & $b_{3}$ & $b_{3}$ & $b_{3}$ & $b_{3}$ & $b_{2}$ & $\mathrm{~b}_{2}$ & $\mathrm{c}_{1}$ \\
\hline $\mathrm{E}_{12}$ & $b_{1}$ & $b_{2}$ & $b_{3}$ & $b_{1}$ & $b_{2}$ & $b_{1}$ & $\mathrm{~b}_{2}$ & $\mathrm{c}_{1}$ \\
\hline $\mathrm{E}_{13}$ & $\mathrm{~b}_{3}$ & $\mathrm{~b}_{2}$ & $\mathrm{~b}_{2}$ & $\mathrm{~b}_{2}$ & $b_{1}$ & $b_{3}$ & $\mathrm{~b}_{1}$ & $\mathrm{c}_{2}$ \\
\hline $\mathrm{E}_{14}$ & $\mathrm{~b}_{3}$ & $b_{3}$ & $b_{3}$ & $b_{3}$ & $b_{3}$ & $b_{3}$ & $b_{3}$ & $\mathrm{c}_{1}$ \\
\hline $\mathrm{E}_{15}$ & $\mathrm{~b}_{1}$ & $b_{1}$ & $b_{1}$ & $b_{1}$ & $b_{1}$ & $b_{1}$ & $b_{1}$ & $\mathrm{c}_{2}$ \\
\hline $\mathrm{E}_{16}$ & $\mathrm{~b}_{1}$ & $\mathrm{~b}_{1}$ & $b_{1}$ & $b_{1}$ & $\mathrm{~b}_{1}$ & $b_{1}$ & $\mathrm{~b}_{1}$ & $\mathrm{c}_{2}$ \\
\hline $\mathrm{E}_{17}$ & $b_{1}$ & $b_{3}$ & $\mathrm{~b}_{2}$ & $\mathrm{~b}_{2}$ & $b_{3}$ & $b_{1}$ & $\mathrm{~b}_{3}$ & $\mathrm{c}_{1}$ \\
\hline $\mathrm{E}_{18}$ & $\mathrm{~b}_{1}$ & $b_{2}$ & $b_{2}$ & $b_{3}$ & $\mathrm{~b}_{2}$ & $b_{1}$ & $\mathrm{~b}_{2}$ & $\mathrm{c}_{2}$ \\
\hline $\mathrm{E}_{19}$ & $\mathrm{~b}_{1}$ & $\mathrm{~b}_{3}$ & $b_{1}$ & $b_{3}$ & $b_{3}$ & $b_{1}$ & $\mathrm{~b}_{3}$ & $\mathrm{c}_{2}$ \\
\hline $\mathrm{E}_{20}$ & $\mathrm{~b}_{1}$ & $b_{3}$ & $b_{1}$ & $b_{3}$ & $\mathrm{~b}_{3}$ & $b_{1}$ & $\mathrm{~b}_{3}$ & $\mathrm{c}_{1}$ \\
\hline
\end{tabular}

The decision table -1 , takes the initial values before finding the reduct looking at the data table it is found that entities $\mathrm{E}_{15} \mathrm{E}_{16}$, are same so keep one record either from $E_{15}$ or $E_{16}$ similarly $E_{3} E_{4}$ has same value so we keep one record either from $E_{3}$ or $E_{4}$ in the next table. $E_{19}$ and $E_{20}$ ambiguous in nature so we drop both from next table, that is table-2

Reduced Table-2 from table-1

\begin{tabular}{|l|l|l|l|l|l|l|l|}
\hline$E$ & $a_{1}$ & $a_{2}$ & $a_{3}$ & $a_{4}$ & $a_{5}$ & $a_{7}$ & $D$ \\
\hline $\mathrm{E}_{1}$ & $\mathrm{~b}_{2}$ & $\mathrm{~b}_{2}$ & $\mathrm{~b}_{1}$ & $\mathrm{~b}_{1}$ & $\mathrm{~b}_{1}$ & $\mathrm{~b}_{1}$ & $\mathrm{c}_{2}$ \\
\hline $\mathrm{E}_{2}$ & $\mathrm{~b}_{2}$ & $\mathrm{~b}_{2}$ & $\mathrm{~b}_{1}$ & $\mathrm{~b}_{3}$ & $\mathrm{~b}_{3}$ & $\mathrm{~b}_{2}$ & $\mathrm{c}_{2}$ \\
\hline $\mathrm{E}_{4}$ & $\mathrm{~b}_{1}$ & $\mathrm{~b}_{2}$ & $\mathrm{~b}_{2}$ & $\mathrm{~b}_{3}$ & $\mathrm{~b}_{3}$ & $\mathrm{~b}_{2}$ & $\mathrm{c}_{1}$ \\
\hline $\mathrm{E}_{5}$ & $\mathrm{~b}_{3}$ & $\mathrm{~b}_{3}$ & $\mathrm{~b}_{3}$ & $\mathrm{~b}_{3}$ & $\mathrm{~b}_{2}$ & $\mathrm{~b}_{2}$ & $\mathrm{c}_{1}$ \\
\hline $\mathrm{E}_{6}$ & $\mathrm{~b}_{1}$ & $\mathrm{~b}_{2}$ & $\mathrm{~b}_{2}$ & $\mathrm{~b}_{2}$ & $\mathrm{~b}_{2}$ & $\mathrm{~b}_{2}$ & $\mathrm{c}_{2}$ \\
\hline $\mathrm{E}_{7}$ & $\mathrm{~b}_{2}$ & $\mathrm{~b}_{2}$ & $\mathrm{~b}_{2}$ & $\mathrm{~b}_{2}$ & $\mathrm{~b}_{2}$ & $\mathrm{~b}_{2}$ & $\mathrm{c}_{1}$ \\
\hline $\mathrm{E}_{8}$ & $\mathrm{~b}_{1}$ & $\mathrm{~b}_{1}$ & $\mathrm{~b}_{1}$ & $\mathrm{~b}_{1}$ & $\mathrm{~b}_{1}$ & $\mathrm{~b}_{1}$ & $\mathrm{c}_{2}$ \\
\hline $\mathrm{E}_{9}$ & $\mathrm{~b}_{1}$ & $\mathrm{~b}_{2}$ & $\mathrm{~b}_{2}$ & $\mathrm{~b}_{3}$ & $\mathrm{~b}_{3}$ & $\mathrm{~b}_{3}$ & $\mathrm{c}_{1}$ \\
\hline $\mathrm{E}_{10}$ & $\mathrm{~b}_{1}$ & $\mathrm{~b}_{2}$ & $\mathrm{~b}_{2}$ & $\mathrm{~b}_{2}$ & $\mathrm{~b}_{2}$ & $\mathrm{~b}_{2}$ & $\mathrm{c}_{2}$ \\
\hline $\mathrm{E}_{11}$ & $\mathrm{~b}_{2}$ & $\mathrm{~b}_{3}$ & $\mathrm{~b}_{3}$ & $\mathrm{~b}_{3}$ & $\mathrm{~b}_{3}$ & $\mathrm{~b}_{2}$ & $\mathrm{c}_{1}$ \\
\hline $\mathrm{E}_{12}$ & $\mathrm{~b}_{1}$ & $\mathrm{~b}_{2}$ & $\mathrm{~b}_{3}$ & $\mathrm{~b}_{1}$ & $\mathrm{~b}_{2}$ & $\mathrm{~b}_{2}$ & $\mathrm{c}_{1}$ \\
\hline $\mathrm{E}_{13}$ & $\mathrm{~b}_{3}$ & $\mathrm{~b}_{2}$ & $\mathrm{~b}_{2}$ & $\mathrm{~b}_{2}$ & $\mathrm{~b}_{1}$ & $\mathrm{~b}_{1}$ & $\mathrm{c}_{2}$ \\
\hline $\mathrm{E}_{14}$ & $\mathrm{~b}_{3}$ & $\mathrm{~b}_{3}$ & $\mathrm{~b}_{3}$ & $\mathrm{~b}_{3}$ & $\mathrm{~b}_{3}$ & $\mathrm{~b}_{3}$ & $\mathrm{c}_{1}$ \\
\hline $\mathrm{E}_{15}$ & $\mathrm{~b}_{2}$ & $\mathrm{~b}_{1}$ & $\mathrm{~b}_{1}$ & $\mathrm{~b}_{1}$ & $\mathrm{~b}_{1}$ & $\mathrm{~b}_{1}$ & $\mathrm{c}_{2}$ \\
\hline $\mathrm{E}_{17}$ & $\mathrm{~b}_{1}$ & $\mathrm{~b}_{3}$ & $\mathrm{~b}_{2}$ & $\mathrm{~b}_{2}$ & $\mathrm{~b}_{3}$ & $\mathrm{~b}_{3}$ & $\mathrm{c}_{1}$ \\
\hline $\mathrm{E}_{18}$ & $\mathrm{~b}_{1}$ & $\mathrm{~b}_{2}$ & $\mathrm{~b}_{2}$ & $\mathrm{~b}_{3}$ & $\mathrm{~b}_{2}$ & $\mathrm{~b}_{2}$ & $\mathrm{c}_{2}$ \\
\hline
\end{tabular}

$$
\begin{aligned}
& E_{\text {positive }}=\left\{E_{4}, E_{5}, E_{7}, E_{9}, E_{11}, E_{12}, E_{14}, E_{17}\right\} \ldots \ldots \ldots(1) \\
& E_{\text {negative }}=\left\{E_{1}, E_{2}, E_{6}, E_{8}, E_{10}, E_{13}, E_{15}, E_{18}\right\} \ldots \ldots \ldots \ldots(2) \\
& E\left(a_{1}\right)_{\text {low }}=\left\{E_{4}, E_{6}, E_{8}, E_{9}, E_{10}, E_{12}, E_{17}, E_{18}\right\} \ldots \ldots \ldots \ldots .(3)
\end{aligned}
$$


$\mathrm{E}\left(\mathrm{a}_{1}\right)_{\text {moderate }}=\left\{\mathrm{E}_{1}, \mathrm{E}_{2}, \mathrm{E}_{7}, \mathrm{E}_{11}, \mathrm{E}_{15}\right\}$

$\mathrm{E}\left(\mathrm{a}_{1}\right)_{\text {high }}=\left\{\mathrm{E}_{5}, \mathrm{E}_{13}, \mathrm{E}_{14}\right\}$

The above result when compared with the positive cases $\mathrm{E}\left(\mathrm{a}_{1}\right)_{\text {high }}$ strength[11] found to be $2 / 3$ about $66 \%$ where as for negative cases of $\mathrm{E}\left(\mathrm{a}_{1}\right)_{\text {low }}$ is $1 / 2$ about $50 \%$ strength[11] $1 / 3$ cent percent similarly for negative cases of moderate $E\left(a_{1}\right)$ strength[11] gives rise to be $3 / 5$ about $60 \%$, so we arrive at a contradiction that we have $66 \%$ positive and $50 \%$ negative and $60 \%$ negative case in moderate case of $a_{1}$ doesn't provide any significance similarly

$\mathrm{E}\left(\mathrm{a}_{2}\right)_{\text {low }}=\left\{\mathrm{E}_{8}, \mathrm{E}_{15}\right\}$

$\mathrm{E}\left(\mathrm{a}_{2}\right)_{\text {moderate }}=\left\{\mathrm{E}_{1}, \mathrm{E}_{2}, \mathrm{E}_{4}, \mathrm{E}_{6}, \mathrm{E}_{7}, \mathrm{E}_{9}, \mathrm{E}_{10}, \mathrm{E}_{12}, \mathrm{E}_{13}, \mathrm{E}_{18}\right\}$

$\mathrm{E}\left(\mathrm{a}_{2}\right)_{\text {high }}=\left\{\mathrm{E}_{5}, \mathrm{E}_{11}, \mathrm{E}_{17}\right\}$

Similar analysis strength[11] positive high $\mathrm{a}_{2}$ will be $4 / 4=1$ about cent percent And for strength[11] negative for low $\mathrm{a}_{2}$ will be also $3 / 3=1$ about cent percent

Provide a strong conclusion regarding the attribute $\mathrm{a}_{2}$, as both cases positive and negative result is about cent percent. So this is an important attribute for further classification now similarly for $\mathrm{a}_{3}$.

$\mathrm{E}\left(\mathrm{a}_{3}\right)_{\mathrm{low}}=\left\{\mathrm{E}_{1}, \mathrm{E}_{2}, \mathrm{E}_{8}, \mathrm{E}_{15}\right\}$

$\mathrm{E}\left(\mathrm{a}_{3}\right)_{\text {moderate }}=\left\{\mathrm{E}_{4}, \mathrm{E}_{6}, \mathrm{E}_{7}, \mathrm{E}_{9}, \mathrm{E}_{10}, \mathrm{E}_{13}, \mathrm{E}_{17}, \mathrm{E}_{18}\right\}$

$\mathrm{E}\left(\mathrm{a}_{3}\right)_{\text {high }}=\left\{\mathrm{E}_{5}, \mathrm{E}_{11}, \mathrm{E}_{12}, \mathrm{E}_{14}\right\}$

Finding the strength [11] high $\mathrm{a}_{3}$ positive cases will be $4 / 4=1$ that is about cent percent nd similarly for strength [11] for low $a_{3}$ cases will be gives negative result will be of $4 / 5$ about $80 \%$ negative cases for low $\mathrm{a}_{3}$ cases so we are not consider the moderate $\mathrm{a}_{3}$ cases as we have a solid conclusion by simple consideration of high and low issues of $a_{3}$ cases now similarly for $\mathrm{a}_{4}$ cases we consider the

$\mathrm{E}\left(\mathrm{a}_{4}\right)_{\text {low }}=\left\{\mathrm{E}_{1}, \mathrm{E}_{8}, \mathrm{E}_{12}, \mathrm{E}_{15}\right\} \ldots$

$\mathrm{E}\left(\mathrm{a}_{4}\right)_{\text {moderate }}=\left\{\mathrm{E}_{6}, \mathrm{E}_{7}, \mathrm{E}_{10}, \mathrm{E}_{13}, \mathrm{E}_{17}\right\}$. . . .

$\mathrm{E}\left(\mathrm{a}_{4}\right)_{\text {high }}=\left\{\mathrm{E}_{2}, \mathrm{E}_{4}, \mathrm{E}_{5}, \mathrm{E}_{9}, \mathrm{E}_{11}, \mathrm{E}_{14}, \mathrm{E}_{18}\right\}$

Analyzing $\mathrm{a}_{4} \mathrm{E}\left(\mathrm{a}_{4}\right)_{\text {low }}$ negative strength[11] will be $4 / 5$ that is about $80 \%$ similarly for $\mathrm{E}\left(\mathrm{a}_{4}\right)_{\text {high }}$ positive strength[11] cases will be about $5 / 7$ about $70 \%$, does not provide any significant result , next we analyze attribute $a_{5}$ for futher analysis

$\mathrm{E}\left(\mathrm{a}_{5}\right)_{\mathrm{low}}=\left\{\mathrm{E}_{1}, \mathrm{E}_{8}, \mathrm{E}_{13}, \mathrm{E}_{15}\right\}$

$\mathrm{E}\left(\mathrm{a}_{5}\right)_{\text {moderate }}=\left\{\mathrm{E}_{5}, \mathrm{E}_{6}, \mathrm{E}_{7}, \mathrm{E}_{10}, \mathrm{E}_{12}, \mathrm{E}_{18}\right\}$

$\mathrm{E}\left(\mathrm{a}_{5}\right)_{\text {high }}=\left\{\mathrm{E}_{2}, \mathrm{E}_{3}, \mathrm{E}_{9}, \mathrm{E}_{11}, \mathrm{E}_{14}, \mathrm{E}_{17}\right\}$

$E\left(a_{5}\right)_{\text {low }}$ strength[11] for negative case will be $4 / 4$ about cent percent and $E\left(a_{5}\right)_{\text {high }}$ strength for positive $4 / 6$ about $66 \%$ positive strength[11] moderate case given by $3 / 8$ about $37 \%$ so after analyzing the above data by strength view point we ignore attribute $a_{1}$ and $a_{5}$ as in $a_{1}$ strength [11] for low negative case is $100 \%$ high positive strength[11] $\mathrm{a}_{1}$ about $20 \%$ similar argument in case of $a_{5}$ observing it's strength[11] now upon analyzing $a_{6}$ it has the following information

$\mathrm{E}\left(\mathrm{a}_{6}\right)_{\mathrm{low}}=\left\{\mathrm{E}_{4}, \mathrm{E}_{6}, \mathrm{E}_{8}, \mathrm{E}_{9}, \mathrm{E}_{10}, \mathrm{E}_{12}, \mathrm{E}_{17}, \mathrm{E}_{18}\right\}$

$\mathrm{E}\left(\mathrm{a}_{6}\right)_{\text {moderate }}=\left\{\mathrm{E}_{1}, \mathrm{E}_{2}, \mathrm{E}_{7}, \mathrm{E}_{11}, \mathrm{E}_{15}\right\}$

$\mathrm{E}\left(\mathrm{a}_{6}\right)_{\text {high }}=\left\{\mathrm{E}_{5}, \mathrm{E}_{13}, \mathrm{E}_{14}\right\}$

Provide the following strength cases $E\left(a_{6}\right)_{\text {high }}$ strength[11] found to be $2 / 3$ about $66 \%$ where as for negative cases of $E\left(a_{6}\right)_{\text {low }}$ is $1 / 2$ about $50 \%$ strength[11] $1 / 3$ cent percent similarly for negative cases of moderate $\mathrm{E}\left(\mathrm{a}_{6}\right)$ strength[11] gives rise to be $3 / 5$ about $60 \%$, so we arrive at a contradiction that we have $66 \%$ positive and $50 \%$ negative and $60 \%$ negative case in moderate case of $a_{1}$ doesn't provide any significance similarly in case of $a_{7}$ there is peculiar case arises that moderate cases of $a_{7}$ provide both positive and negative result , so we arrive at an ambiguity ,that's why we don't analyze $a_{7}$ further

In table-3 we drop $a_{1}, a_{5}, a_{7}$. So after dropping $a_{1}, a_{5}$, and $a_{7}$ from table 2 we have the new reduct table, named as table- 3 .

Reduced Table- 3 from Table- 2

\begin{tabular}{|l|l|l|l|l|}
\hline$E$ & $a_{2}$ & $a_{3}$ & $a_{4}$ & $D$ \\
\hline $\mathrm{E}_{1}$ & $\mathrm{~b}_{2}$ & $\mathrm{~b}_{1}$ & $\mathrm{~b}_{1}$ & $\mathrm{c}_{2}$ \\
\hline $\mathrm{E}_{2}$ & $\mathrm{~b}_{2}$ & $\mathrm{~b}_{1}$ & $\mathrm{~b}_{3}$ & $\mathrm{c}_{2}$ \\
\hline $\mathrm{E}_{4}$ & $\mathrm{~b}_{2}$ & $\mathrm{~b}_{2}$ & $\mathrm{~b}_{3}$ & $\mathrm{c}_{1}$ \\
\hline $\mathrm{E}_{5}$ & $\mathrm{~b}_{3}$ & $\mathrm{~b}_{3}$ & $\mathrm{~b}_{3}$ & $\mathrm{c}_{1}$ \\
\hline $\mathrm{E}_{6}$ & $\mathrm{~b}_{2}$ & $\mathrm{~b}_{2}$ & $\mathrm{~b}_{2}$ & $\mathrm{c}_{2}$ \\
\hline $\mathrm{E}_{7}$ & $\mathrm{~b}_{2}$ & $\mathrm{~b}_{2}$ & $\mathrm{~b}_{2}$ & $\mathrm{c}_{1}$ \\
\hline $\mathrm{E}_{8}$ & $\mathrm{~b}_{1}$ & $\mathrm{~b}_{1}$ & $\mathrm{~b}_{1}$ & $\mathrm{c}_{2}$ \\
\hline $\mathrm{E}_{9}$ & $\mathrm{~b}_{2}$ & $\mathrm{~b}_{2}$ & $\mathrm{~b}_{3}$ & $\mathrm{c}_{1}$ \\
\hline $\mathrm{E}_{10}$ & $\mathrm{~b}_{2}$ & $\mathrm{~b}_{2}$ & $\mathrm{~b}_{2}$ & $\mathrm{c}_{2}$ \\
\hline $\mathrm{E}_{11}$ & $\mathrm{~b}_{3}$ & $\mathrm{~b}_{3}$ & $\mathrm{~b}_{3}$ & $\mathrm{c}_{1}$ \\
\hline $\mathrm{E}_{12}$ & $\mathrm{~b}_{2}$ & $\mathrm{~b}_{3}$ & $\mathrm{~b}_{1}$ & $\mathrm{c}_{1}$ \\
\hline $\mathrm{E}_{13}$ & $\mathrm{~b}_{2}$ & $\mathrm{~b}_{2}$ & $\mathrm{~b}_{2}$ & $\mathrm{c}_{2}$ \\
\hline $\mathrm{E}_{14}$ & $\mathrm{~b}_{3}$ & $\mathrm{~b}_{3}$ & $\mathrm{~b}_{3}$ & $\mathrm{c}_{1}$ \\
\hline $\mathrm{E}_{15}$ & $\mathrm{~b}_{1}$ & $\mathrm{~b}_{1}$ & $\mathrm{~b}_{1}$ & $\mathrm{c}_{2}$ \\
\hline $\mathrm{E}_{16}$ & $\mathrm{~b}_{1}$ & $\mathrm{~b}_{1}$ & $\mathrm{~b}_{1}$ & $\mathrm{c}_{2}$ \\
\hline $\mathrm{E}_{17}$ & $\mathrm{~b}_{3}$ & $\mathrm{~b}_{2}$ & $\mathrm{~b}_{2}$ & $\mathrm{c}_{1}$ \\
\hline $\mathrm{E}_{18}$ & $\mathrm{~b}_{2}$ & $\mathrm{~b}_{2}$ & $\mathrm{~b}_{3}$ & $\mathrm{c}_{2}$ \\
\hline
\end{tabular}

Upon analyzing table-3 we have the following result that is $\left(\mathrm{E}_{5}, \mathrm{E}_{11}, \mathrm{E}_{14}\right),\left(\mathrm{E}_{8}, \mathrm{E}_{15}, \mathrm{E}_{16}\right),\left(\mathrm{E}_{10}, \mathrm{E}_{13}\right)$, forms group and $\left(\mathrm{E}_{6}, \mathrm{E}_{7}\right)$ $\left(\mathrm{E}_{9}, \mathrm{E}_{9}, \mathrm{E}_{18}\right)$,ambiguous so we keep on record for each group and delete all records which give ambiguous result so we have the new table appears as table- 4 given as follows

Reduced Table- 4 from Table- 3

\begin{tabular}{|l|l|l|l|l|}
\hline$E$ & $a_{2}$ & $a_{3}$ & $a_{4}$ & $D$ \\
\hline $\mathrm{E}_{1}$ & $\mathrm{~b}_{2}$ & $\mathrm{~b}_{1}$ & $\mathrm{~b}_{1}$ & $\mathrm{c}_{2}$ \\
\hline $\mathrm{E}_{2}$ & $\mathrm{~b}_{2}$ & $\mathrm{~b}_{1}$ & $\mathrm{~b}_{3}$ & $\mathrm{c}_{2}$ \\
\hline $\mathrm{E}_{5}$ & $\mathrm{~b}_{3}$ & $\mathrm{~b}_{3}$ & $\mathrm{~b}_{3}$ & $\mathrm{c}_{1}$ \\
\hline $\mathrm{E}_{8}$ & $\mathrm{~b}_{1}$ & $\mathrm{~b}_{1}$ & $\mathrm{~b}_{1}$ & $\mathrm{c}_{2}$ \\
\hline $\mathrm{E}_{10}$ & $\mathrm{~b}_{2}$ & $\mathrm{~b}_{2}$ & $\mathrm{~b}_{2}$ & $\mathrm{c}_{2}$ \\
\hline $\mathrm{E}_{12}$ & $\mathrm{~b}_{2}$ & $\mathrm{~b}_{3}$ & $\mathrm{~b}_{1}$ & $\mathrm{c}_{1}$ \\
\hline $\mathrm{E}_{17}$ & $\mathrm{~b}_{3}$ & $\mathrm{~b}_{2}$ & $\mathrm{~b}_{2}$ & $\mathrm{c}_{1}$ \\
\hline
\end{tabular}

As we observe $E_{8}$ and $E_{10}$ has conditional attributes values different but giving same decision so we safely drop both for futher classification

Further reduction of Table -4 is not possible

From the table we are develop an algorithm is as follows

1. Moderate $\mathrm{a}_{2}$, low $\mathrm{a}_{3}$ and is provide negative result

2. Moderate $\mathrm{a}_{2}$ and non significant $\mathrm{a}_{4}$ and significant $\mathrm{a}_{3}$, leads to negative result

3. High or severe $\mathrm{a}_{2}$ and significant $\mathrm{a}_{4}$ leads to positive case

4. $a_{2}$ is not significant, no significant $a_{3}$ present, non significant $a_{4}$ implies negative cases of feedback system

5. Moderate $a_{2}$, significant $a_{3}$ non significant $a_{3}$ leads to 
positive cases for feed back system

6. Severe $a_{2}, a_{3}$ partially significant, $a_{4}$ is partially significant leads to positive cases for the feedback system

The above algorithm gives us a conclusion that decision attributes $a_{2}, a_{5}, a_{3}$ is essential components of decision making in case of feedback system to provide accuracy we then statistically validate our claims

Statistical validation I- To validate our findings we basically depends upon chi-square test for this purpose we consider we take a survey by taking data regarding the success of the feedback system around the globe and we are collecting the information from various sources then applying chi square test to validate our claim. With respect to the observed data Chi square test- Expected $15 \%, 10 \%, 15 \%, 20 \%, 30 \%, 15 \%$ and the Observed samples are $25,14,3445,62,20$ so totaling these we have total of 200 samples so expected numbers of samples per each day as follows $30,20,30,40,60,30$. We then apply chi square distribution to verify our result assuming that $\mathrm{H}_{0}$ is our hypothesis that is correct $\mathrm{H}_{1}$ as alternate hypothesis that is not correct, Then we expect sample in six cases as chi squared estimation formula is $\sum\left(\mathrm{O}_{\mathrm{i}}-\mathrm{E}_{\mathrm{i}}\right)^{2} / \mathrm{E}_{\mathrm{i}}$ where $\mathrm{i}=0,1,2,3,4,5$ so the calculated as follows

$\mathrm{X}^{2}=(25-30)^{2} / 30+(14-20)^{2} / 20+(34-30)^{2} / 30+(45-40)^{2} / 40+(62-$

$60)^{2} / 60+(20-30)^{2} / 30$

$\mathrm{X}^{2}=25 / 20+36 / 20+16 / 30+25 / 40+4 / 60+100 / 30$

$=7.60$

The tabular values we have with degree of freedom 5 we get result 11.04. This result is well below the tabular values, this gives us to accept our claim.

\section{Statistical validation II-}

Chi square test- Expected $14 \%, 16 \%, 15.5 \%, 21 \%, 31 \%, 14 \%$ and the samples are $26,18,34,43,61,20$. so totaling these we have total of 200 samples so expected numbers of samples per each day as follows $28,32,31,42,62,28$. We then apply chi square distribution to verify our result assuming that $\mathrm{H}_{0}$ is our hypothesis that is correct $\mathrm{H}_{1}$ as alternate hypothesis that is not correct, Then we expect sample in six cases as chi squared estimation formula is $\sum\left(\mathrm{O}_{\mathrm{i}}-\mathrm{E}_{\mathrm{i}}\right)^{2} / \mathrm{E}_{\mathrm{i}}$ where $\mathrm{i}=0,1,2,3,4,5$ so the calculated as follows 8.879 it is far below the tabular values 11.04 wit degrees of freedom 5 so we accept our claim.+

Conclusion -We conclude with this note, our work is based the greedy choice not accounting the dynamic nature of the process .
Choosing the optimality accounting best availability at a particular time instance

Note- $a_{1}, a_{2}, a_{3}, a_{4}, a_{5}, a_{6}, a_{7}$ has it's usual meaning define above

Future Work- This idea can be extend to entertainment, Business logic development and in the Field of agriculture, Entertainment and Education.

\section{REFERENCES}

[1] Cios, K., W. Pedrycz and R. Swiniarski (1998). Data Mining Methods for Knowledge Discovery. Kluwer Academic

[2] Wolf, S., H. Oliver, S. Herbert and M. Michael (2000). Intelligent data mining for medical quality management

[3] Se-Ho, Ch., and P. Rockett (2002). The training of neural classifiers with condensed datasets. SMCB, 32(2), 202-206.

[4] Cheeseman, P., and J. Stutz (1996). Bayesian classification (AutoClass): theory and results. In U.M.Fayyad

[5] Grzymala-Busse, J., Z. Pawlak, R. Slowinski and W. Ziarko (1999). Rough sets. Communications of the ACM

[6] Hassanien, A.E. (2003). Classification and feature selection of breast cancer data based on decision tree algorithm

[7] Parido, A., and P. Bonelli (1993). A new approach to fuzzy classifier systems. In Proceedings of the FifthInternational Conference on Genetic Algorithms. pp. 223-230

[8] Setiono, R. (2000). Generating concise and accurate classification rules for breast cancer diagnosis. Artificial Intelligence in Medicine, 18(3), 205-219

[9] Lin, T.Y., and N. Cercone (1997). Rough Sets and Data Mining. Kluwer Academic Publishers.Ning, S., H. Xiaohua, W. Ziarko and N. Cercone (1994). A generalized rough sets model. In Proceedings ofthe 3rd Pacific Rim International Conference on Artificial Intelligence, Vol. 431. Beijing, China. Int. Acad.Publishers. pp. 437-443.

[10] Pawlak, Z. (1991). Rough Sets-Theoretical Aspect of Reasoning about Data. Kluwer Academic Publishers.

[11] Pawlak, Z., J. Grzymala-Busse, R. Slowinski, W. Ziarko (1995). Rough sets. Communications of the ACM

[12] Renu Vashist Prof M.L Garg Rule Generation based on Reduct and Core :A rough set approach International Journal of Computer Application(0975-887) Vol 29 September -2011 Page 1-4 